\title{
Zonas úmidas, de Charlotte Roche
}

\author{
Simone Gonçalves
}

Com a publicação de seu primeiro romance Zonas úmidas, ${ }^{1}$ a ex-apresentadora de tevê e ganhadora do prêmio de televisão Grimme-Preis, Charlotte Roche, 30, desencadeou um estardalhaço na mídia alemã em 2008. O livro logo alcançou o topo da lista dos bestsellers, foi adaptado para o teatro e continua na lista dos mais vendidos, publicada pela revista Spiegel. Nenhum outro lançamento do ano passado provocou na Alemanha tanto entusiasmo e indignação ao mesmo tempo, como esse romance. Consoante às palavras do ícone da crítica literária na Alemanha, Marcel Reich-Ranicki, "Isso não é literatura, mas sim um livro pornográfico! A mulher não tem estilo, isso não é um estilo ruim, isso não é estilo!"”. Já o crítico alemão Roger Willemsen diz: "Radical, drástico e igualmente delicado. Não me lembro de ter tido nas mãos um manuscrito de estreia tão seguro, tão arrojado e atual como este".

A protagonista de Zonas úmidas, Helen Memel, 18, que durante uma depilação íntima fere sua "hemorroida com aspecto de couve-flor", passa toda a ação do romance em um hospital, de onde procura levar ao leitor suas experiências com o próprio corpo. A narradora lança mão de uma linguagem sem rodeios e preocupa-

Feuchtgebiete [Zonas úmidas] 2008, Editora DuMont Buchverlag, Colônia, 5ª edição, $220 \mathrm{p}$. 
ções eufemísticas. Helen fala sem pudor de secreções do corpo, técnicas de masturbação e detalhes que antes provocam nojo do que aguçam a fantasia do leitor.

A autora, que confessa não ser nenhuma bibliófila e, em cinco anos, desde o nascimento de sua filha, não ter lido sequer um livro, pretendia a princípio menos escrever um romance do que um manifesto contra a submissão a padrões de higiene impostos por uma cultura voltada para o consumo. A ação minimalista de Zonas úmidas serve para a classificação no gênero romance, o que torna a leitura mais entretida e consequentemente atinge um público maior.

A linguagem é simples e não apresenta as dificuldades mais comuns da tradução do alemão para o português, como palavras compostas de mais de dois substantivos, adjetivação abundante ou especificidade cultural sem equivalência na língua-alvo. Contudo, o principal desafio na tradução de Zonas úmidas consiste na escolha subjetiva dentro do campo semântico do grotesco.

Que "pornografia" ainda consiga causar tanto alvoroço no esclarecido século 21 deve-se ao valor desse romance incipiente, ao seu discurso radical e direto sobre o corpo feminino, que se opõe implacavelmente ao mundo estetizante que nos é insinuado no dia a dia. A provocação consiste em falar de sexualidade dispensando o selo de qualidade sexy. 


\section{Feuchtgebiete}

Solange ich denken kann, habe ich Hämorrhoiden. Viele, viele Jahre habe ich gedacht, ich dürfte das keinem sagen. Weil Hämorrhoiden doch nur bei Opas wachsen. Ich fand die immer sehr unmädchenhaft. Wie oft ich mit denen schon beim Proktologen war! Der hat mir aber empfohlen, die dran zu lassen, solange sie mir keine Schmerzen verursachen. Das taten sie nicht. Sie juckten nur. Dagegen bekam ich von meinem Proktologen Dr. Fiddel eine Zinksalbe.

Für das äußere Gejucke drückt man aus der Tube eine haselnussgroße Menge auf den Finger mit dem kürzesten Nagel und verreibt sie auf der Rosette. Die Tube hat auch so einen spitzen Aufsatz mit vielen Löchern drin, damit ich die anal einführen und da hinspritzen kann, um den Juckreiz sogar innen zu stillen.

Bevor ich so eine Salbe hatte, hab ich mich im Schlaf so feste mit einem Finger am und im Poloch gekratzt, dass ich am nächsten Morgen einen kronkorkengroßen dunkelbraunen Fleck in der Unterhose hatte. So stark war der Juckreiz, so tief der Finger drin. Sag ich ja: sehr unmädchenhaft.

Meine Hämorrhoiden sehen ganz besonders aus. Im Laufe der Jahre haben die sich immer mehr nach außen gestülpt. Einmal rund um die Rosette sind jetzt wolkenförmige Hautlappen, die aussehen wie die Fangarme einer Seeanemone. Dr. Fiddel nennt das Blumenkohl.

Er sagt, wenn ich das weghaben will, wäre das ein rein ästhetischer Eingriff. Er macht das nur weg, wenn es die Leute wirklich belastet. Gute Gründe wären, wenn es meinem Liebhaber nicht gefällt oder ich wegen meinem Blumenkohl beim Sex Beklemmungen kriege. Das würde ich aber nie zugeben.

Wenn einer mich liebt oder auch nur geil auf mich ist, dann sollte doch so ein Blumenkohl keine Rolle spielen. Außerdem habe ich schon viele Jahre, von fünfzehn bis heute, mit achtzehn, trotz eines wuchernden Blumenkohls sehr erfolgreich Analverkehr. Sehr 
erfolgreich heißt für mich: kommen, obwohl der Schwanz nur in meinem Arsch steckt und sonst nix berührt wird. Ja, da bin ich stolz drauf.

So teste ich übrigens am besten, ob es einer ernst mit mir meint: Ich fordere ihn schon bei einem der ersten Sexe zu meiner Lieblingsstellung auf: ich in Doggystellung, also auf allen vieren, Gesicht nach unten, er von hinten kommend Zunge in die Muschi, Nase in den Arsch, da muss man sich geduldig vorarbeiten, weil das Loch ja von dem Gemüse verdeckt wird. Die Stellung heißt "MitDem-Gesicht-Gestopft". Hat sich noch keiner beschwert.

Wenn man so was an einem für Sex wichtigen Organ hat (ist der Po überhaupt ein Organ?), muss man sich in Entspanntheit üben. Das wiederum hilft beim Sichfallenlassen und Lockermachen für zum Beispiel Analverkehr.

Da bei mir der Arsch offensichtlich zum Sex dazugehört, ist er auch diesem modernen Rasurzwang unterworfen wie meine Muschi, meine Beine, meine Achselhöhlen, der Oberlippenbereich, beide großen Zehen und die Fußrücken auch. Die Oberlippe wird natürlich nicht rasiert, sondern gezupft, weil wir alle gelernt haben, dass einem sonst ein immer dickerer Schnurrbart wächst. Als Mädchen gilt es das zu verhindern. Früher war ich unrasiert sehr glücklich, aber dann habe ich mit dem Quatsch mal angefangen und kann jetzt nicht mehr aufhören.

Zurück zum Arschrasieren. Ich weiß im Gegensatz zu anderen Menschen sehr genau, wie mein Poloch aussieht. Ich gucke es täglich in unserem Badezimmer an. Mit dem Po zum Spiegel hinstellen, mit beiden Händen die Arschbacken feste auseinanderziehen, Beine gerade lassen, mit dem Kopf fast auf den Boden und durch die Beine nach hinten gucken. Genauso führe ich auch eine Arschrasur durch. Nur dass ich dabei natürlich immer eine Backe loslassen muss, um rasieren zu können. Der Nassrasierer wird auf den Blumenkohl gesetzt und dann wird mutig und feste von innen nach außen rasiert. Ruhig auch bis zur Mitte der Backe, manchmal verirrt sich auch dahin 
ein Haar. Weil ich mich innerlich sehr gegen das Rasieren wehre, mache ich das immer viel zu schnell und zu dolle. Genau dabei hab ich mir diese Analfissur zugefügt, wegen der ich jetzt im Krankenhaus liege. Alles das Ladyshaven schuld. Feel like Venus. Be a goddess!

Es weiß vielleicht nicht jeder, was eine Analfissur ist. Das ist ein haarfeiner Riss oder Schnitt in der Rosettenhaut. Und wenn sich diese kleine, offene Stelle auch noch entzündet, was da unten leider sehr wahrscheinlich ist, dann tut das höllisch weh. Wie bei mir jetzt. Das Poloch ist auch immer in Bewegung. Wenn man redet, lacht, hustet, geht, schläft und vor allem, wenn man auf Klo sitzt. Das weiß ich aber erst, seit es wehtut.

Die geschwollenen Hämorrhoiden drücken jetzt mit aller Kraft gegen meine Rasurverletzung, lassen die Fissur immer weiter reißen und verursachen mir die größten Schmerzen, die ich je hatte. Mit Abstand. Direkt danach auf Platz zwei kommt der Schmerz, den ich hatte, als mir mein Vater die Kofferraumklappe unseres Autos die ganze Wirbelsäule entlanggeschrabbt hat - ratatatatat - beim volle Pulle Zuschlagen. Und mein drittschlimmster Schmerz war, als ich beim Pulloverausziehen mein Brustwarzenpiercing rausgerissen hab. Weswegen meine rechte Brustwarze jetzt aussieht wie eine Schlangenzunge.

Zurück zu meinem Po. Ich habe mich unter riesigen Schmerzen von der Schule ins Krankenhaus geschleppt und jedem Doktor, der wollte, meinen Riss gezeigt. Ich habe sofort ein Bett in der Proktologischen Abteilung gekriegt, oder sagt man Innere Abteilung? Innere klingt besser als so speziell Arschabteilung zu sagen. Man will ja nicht, dass andere neidisch werden. Vielleicht verallgemeinert man das mit Innere. Frage ich später mal, wenn die Schmerzen weg sind. Jetzt darf ich mich jedenfalls nicht mehr bewegen und liege hier in Embryonalstellung rum. Mit hochgeschobenem Rock und runtergelassener Unterhose, Arsch zur Tür. Damit jeder, der reinkommt, sofort weiß, was Sache ist. Es muss sehr entzündet aussehen. Alle, die reinkommen, sagen: "Oh." 
Und reden was von Eiter und einer prall gefüllten Wundwasserblase, die aus dem Poloch raushängt. Ich stelle mir vor, dass die Blase aussieht wie die Halshaut von diesen tropischen Vögeln, wenn sie da zum Brunftangeben ganz viel Luft reinpumpen. Ein glänzendrotblau gespannter Sack. Der nächste Proktologe, der reinkommt, sagt kurz: “Guten Tag, Professor Dr. Notz mein Name."

Und rammt mir dann was ins Arschloch. Der Schmerz bohrt sich die Wirbelsäule hoch bis zur Stirn. Ich verliere fast das Bewusstsein. Nach ein paar Schmerzsekunden habe ich ein platzendes, nasses Gefühl und schreie: “Aua, vorwarnen, bitte. Was war das, verdammt?"

Und er: "Mein Daumen. Entschuldigen Sie bitte, mit der dicken Blase davor konnte ich nichts sehen."

Was für eine Art, sich vorzustellen! "Und? Was sehen Sie jetzt?"

"Wir müssen sofort operieren. Heute Morgen schon was gegessen?"

“Wie denn, vor lauter Schmerzen?"

"Gut, dann Vollnarkose. Bei dem Befund besser."

Ich freu mich auch. Ich will bei so was nicht dabei sein. "Was machen Sie genau bei der Operation?"

Dieses Gespräch strengt mich jetzt schon an. Es ist schwer, sich auf was anderes als die Schmerzen zu konzentrieren.

"Wir schneiden Ihnen das entzündete Gewebe um den Hautriss keilförmig raus."

"Kann ich mir nichts drunter vorstellen: keilförmig. Können Sie mir das aufmalen?"

Offensichtlich wird Herr Professor Dr. Notz nicht oft gebeten, seine operativen Vorhaben vorher kurz zu skizzieren. Er will weg, Blick zur Tür, kaum wahrnehmbares Seufzen.

Dann zieht er sich doch den silbernen Kugelschreiber von der Brusttasche. Sieht schwer aus. Scheint wertvoll zu sein. Er guckt sich um und sucht wohl Papier zum Zeichnen. Ich kann nicht mithelfen, 
ich hoffe, das erwartet der auch nicht. Jede Bewegung tut weh. Ich schließe die Augen.

Es knistert und ich höre, wie er ein Stück Papier irgendwo abreißt. Ich muss die Augen wieder öffnen, bin zu gespannt auf diese Zeichnung. Er hält den Zettel in seiner Handfläche und macht mit dem Kugelschreiber darin rum. Dann präsentiert er sein Werk. Ich lese: "Rahmwirsing". Das gibt es nicht. Er hat ein Stück aus meiner Speisekarte gerissen. Ich drehe das Papier um. Er hat einen Kreis gemalt, ich schätze mal, dass es mein Poloch sein soll. Und in den Kreis einen spitzen, dreieckigen Spalt, als hätte jemand ein Stück Torte geklaut. 
Simone Gonçalves. Zonas úmidas, de Charlotte Roche

\section{Zonas úmidas}

Desde que me entendo por gente, tenho hemorroidas. Durante muitos e muitos anos pensei que não podia dizer isso a ninguém, pois hemorroidas crescem apenas em vovôs. Sempre achei que não eram coisa de menina. E quantas vezes não estive com elas no proctologista! Mas ele me recomendou deixá-las ali, enquanto não me causassem dor. Elas não doíam, apenas coçavam. Como remédio recebi do meu proctologista, dr. Fiddel, uma pomada de zinco.

Para a coceira externa, aperta-se o tubo, tirando uma quantidade do tamanho de uma avelã no dedo com a unha mais curta e passa-se a pomada no cu. O tubo tem também um aplicador pontudo com vários buracos para se injetar a pomada, inserindo-o no ânus, a fim de aliviar também a coceira interna.

Antes de eu ter uma pomada dessas, coçava durante o sono com um dedo por fora e por dentro do ânus com tanta força que na manhã seguinte tinha na calcinha uma mancha marrom escura, do tamanho de uma tampinha. Quanto mais forte a coceira, mais fundo entrava o dedo. Pois digo: isso não é coisa de menina.

Minhas hemorroidas têm um aspecto bem especial. No decorrer dos anos, elas foram ficando cada vez mais protuberantes. Em volta da roseta há agora pelancas em forma de nuvem que parecem tentáculos de uma anêmona-do-mar. O dr. Fiddel chama isso de couve-flor.

Ele diz que se eu quiser tirá-las, seria uma intervenção puramente estética. Ele só as opera se realmente incomodarem. Bons motivos seriam se meu amante não gostasse ou se eu não me sentisse à vontade durante a transa. Mas isso eu jamais admitiria.

Se alguém me ama ou apenas está com tesão por mim, então uma couve-flor não deveria ter nenhuma importância. Além disso, já há muitos anos, dos quinze até agora, com dezoito, sempre tive muito sucesso com sexo anal, apesar de uma couve-flor ex- 
crescente. Com sucesso significa para mim: gozar, ainda que o pau só esteja enfiado no meu cu e nada mais seja tocado. É, aí eu me sinto orgulhosa.

Aliás, assim é a melhor maneira de testar se estão me levando a sério: em uma das primeiras transas já proponho minha posição favorita: eu de cachorrinho, ou seja, de quatro e com o rosto para baixo. Ele por detrás, a língua na xereca, o nariz no cu. Aí é preciso se preparar com paciência, pois o buraco fica tapado pela verdura. A posição se chama "com-a-cara-socada". Ninguém se queixou ainda.

Quando se tem isso em um órgão importante para o sexo (e a bunda é por acaso um órgão?), é preciso treinar a descontração, o que por sua vez ajuda a se entregar e a se soltar para o sexo anal, por exemplo.

Como para mim é evidente que o cu faz parte do sexo, ele também está submetido a essa moderna obrigação de depilar-se, como minha xereca, minhas pernas, axilas, a área dos lábios superiores, os dois grandes artelhos e o dorso do pé. É claro que o lábio superior não é raspado, mas os pelos são arrancados, pois todas aprendemos que, do contrário, cresce um bigode espesso. Uma menina deve impedir que isso aconteça. Antigamente eu não me raspava, porém era muito feliz, mas então comecei com essa bobagem e agora não posso mais parar.

Voltemos à depilação do cu. Ao contrário de outras pessoas, sei muito bem como é o meu buraquinho. Eu me olho diariamente no nosso banheiro. Com a bunda de frente para o espelho, abro as nádegas com as mãos, deixo as pernas eretas, e, com a cabeça quase no chão, olho para o espelho através das pernas. É assim que depilo o cu, a única coisa é que preciso soltar uma nádega para poder raspálas. A gilete é posta sobre a couve-flor e então se raspa com coragem e firmeza de dentro para fora. Calmamente também até a metade da nádega, onde às vezes se depara com um pelo perdido. Como no fundo sou contra depilação, me raspo sempre depressa demais e com muita força. Foi assim que me infligi essa fissura anal e por 
causa dela estou agora aqui no hospital. Tudo culpa da Ladyshave. Feel like Venus. Be a goddess!

Talvez nem todo mundo saiba o que é uma fissura anal. É uma rasgadura do tamanho de um fio de cabelo ou um corte na pele da roseta. E quando essa pequena parte aberta inflama, o que infelizmente lá embaixo é muito provável, então dói pra diabo, como agora. O cu está sempre em movimento, quando se fala, se ri, se tosse, se anda, se dorme e, sobretudo, quando se está sentado no vaso. Só sei disso, desde que está doendo.

As hemorroidas inchadas pressionam agora com toda a força meu ferimento decorrente da raspagem; fazem a fissura abrir cada vez mais e me causam a maior dor que já senti na vida. De longe a maior. Direto em segundo lugar está a dor que tive quando meu pai bateu com toda a força a porta do porta-malas do nosso carro na minha coluna vertebral - ra-tá-tá-tá-tá-tá. E minha terceira maior dor foi quando, despindo o pulôver, arranquei o piercing do meu mamilo. Por isso que meu mamilo direito parece agora uma língua de cobra.

De volta à minha bunda. Eu me arrastei, com a maior dor, da escola para o hospital, e mostrei minha fissura a todo médico que queria ver. Recebi imediatamente uma cama na unidade de proctologia, ou será que se diz estação de medicina interna? Interna soa melhor que dizer de forma tão específica, estação anal. Não se quer causar inveja nos outros. Talvez se generalize isso com interna. Vou perguntar depois, quando passar a dor. Em todo caso, agora não posso mais me mexer e estou aqui deitada em posição fetal. Com a saia levantada e com a calcinha abaixada, com a bunda para a porta, para que todos que entrarem aqui saibam qual é o negócio. Precisa estar muito infeccionado. Todos que entram aqui dizem: "Oh!"

E falam de pus e de uma bolha cheia de água, pendurada para fora do ânus. Imagino que essa bolha se assemelhe à pele do pescoço desses pássaros tropicais quando estão em época de acasalamento e se inflam de ar. Um saco teso de um azul avermelhado e brilhoso. 
O próximo proctologista que entra diz de maneira concisa: "Bomdia, sou o prof. dr. Notz".

E me enfia algo no cu. A dor sobe da coluna até a testa. Quase perco os sentidos. Após alguns segundos de dor, tenho uma sensação úmida de algo arrebentando e grito:

- Ai! Avise por favor! O que foi isso, droga?

E ele:

- Foi o meu polegar, por favor, me desculpe. Com aquela bolha grande na frente não podia ver.

Que jeito de se apresentar!

- E então? O que o senhor está vendo agora?

- Precisamos operar imediatamente. Já comeu alguma coisa hoje de manhã?

- Como então com essa dor toda?

- Bem, então anestesia geral, melhor nesse caso.

Também fico satisfeita, pois numa situação dessas não quero estar presente.

- O que é que o senhor faz especificamente durante a operação?

Esse diálogo já me deixa cansada agora. É difícil se concentrar em outra coisa que não na dor.

- Vamos retirar por incisão cuneiforme o tecido infeccionado em volta da fissura.

- Não consigo imaginar como. Cuneiforme. O senhor poderia desenhar para mim?

Fica evidente que o sr. prof. dr. Notz não é solicitado com frequência a esboçar suas intenções cirúrgicas. Ele quer sair, com o olhar para a porta, um suspiro quase imperceptível.

Mas então tira a caneta de prata do bolso da camisa. Parece pesada e de valor. Ele olha em volta procurando papel para desenhar. Não posso ajudar e espero que ele também não esteja com essa expectativa. Todo movimento dói. Eu fecho os olhos. 
Simone Gonçalves. Zonas úmidas, de Charlotte Roche

Há um estalo e aí o escuto arrancando um pedaço de papel em algum lugar. Abro novamente os olhos, estou ansiosa demais com este desenho. Ele segura um papelzinho na palma da mão e faz um movimento com a caneta esferográfica. E então apresenta a sua obra. Leio: "couve lombarda com creme de leite". Não é possível. Ele arrancou um pedaço do meu cardápio. Eu viro o papel. Ele desenhou um círculo, suponho que seja meu ânus. E no círculo uma fenda pontiaguda e triangular, como se alguém tivesse roubado um pedaço de torta. 